EPIDEMIOLOGY

\title{
Relationship between birth weight and adult lung function: controlling for maternal factors
}

\author{
C A Edwards, L M Osman, D J Godden, D M Campbell, J G Douglas
}

Thorax 2003;58:1061-1065

See end of article for authors' affiliations

.....................

Correspondence to: Dr J G Douglas, Chest Clinic, Aberdeen Royal Infirmary, Aberdeen AB25 2ZN, UK; i.g.douglas@ arh.grampian.scot.nhs.uk

Received 26 August 2003 Accepted 28 August 2003

\begin{abstract}
Background: There is conflicting evidence on the "fetal origins hypothesis" of association between birth weight and adult lung function. This may be due to failure to control for confounding maternal factors influencing birth weight. In the present study access to birth details for adults aged 45-50 years who were documented as children to have asthma, wheezy bronchitis, or no respiratory symptoms provided an opportunity to investigate this association, controlling for maternal factors.

Methods: In 2001 the cohort was assessed for current lung function, smoking status, and respiratory symptoms. Birth details obtained from the Aberdeen Maternity and Neonatal Databank recorded birth weight, gestation, parity, and mother's age and height.

Results: 381 subjects aged $45-50$ years were traced and tested for lung function; $323(85 \%)$ had birth details available. A significant linear trend $(p<0.01)$ was observed between birth weight and current forced expiratory volume in 1 second $\left(\mathrm{FEV}_{1}\right.$ ) and forced vital capacity (FVC) values (adjusted for height, age, sex, weight, deprivation category (Depcat), childhood group, and smoking status). This trend remained significant after adjusting birth weight for gestation, parity, sex, mother's height and weight $(p=0.01)$. The relationship between birth weight and $\mathrm{FEV}_{1}$ and $\mathrm{FVC}$ remained significant when adjusted for smoking history. There was no association between birth weight and current wheezing symptoms.

Conclusion: There is a positive linear trend between birth weight, adjusted for maternal factors, and lung function in adulthood. The strength of this association supports the "fetal origins hypothesis" that impairment of fetal growth is a significant influence on adult lung function.
\end{abstract}

$\mathrm{F}$ tal growth and duration of gestation are two of the major influences on lung development. ${ }^{1}$ Anything that adversely affects normal pregnancy may affect lung development in utero. It has been postulated that an adverse environment in utero can retard weight gain of the fetus which, in turn, can constrain the growth of the airways with effects that persist into late adulthood and old age. ${ }^{2}$

In a study of 5000 men aged $59-70$ years born in Hertfordshire in the early 1900s, Barker et al showed that mean forced expiratory in 1 second $\left(\mathrm{FEV}_{1}\right)$ fell with decreasing birth weight but found no association between birth weight and forced vital capacity (FVC) or current wheeze. ${ }^{2}$ Stein et al found an association between birth weight and both $\mathrm{FEV}_{1}$ and FVC in a study of nearly 300 Indian men and women aged 38-59 years. ${ }^{3}$ However, Shaheen et al found no association between birth weight and lung function in a group of 200 men and women with a mean age of 58 years born in St Andrews. ${ }^{4}$ Lopuhää et al observed an increased prevalence of obstructive airways disease in people aged 50 years exposed to famine in mid and early gestation, but there was no association between lung function or prevalence of respiratory symptoms and birth weight. $^{5}$

This conflicting evidence could be due to lack of control for maternal factors that influence birth weight but do not imply an adverse environment in utero. Maternal height and body mass index have significant independent effects on birth weight. ${ }^{67}$ Campbell et al reported that birth weight is not normally distributed at each week of gestation and that standardisation for parity, gestation, and sex of the baby is essential in any study looking at long term effects of differences in fetal growth. ${ }^{8}$ This procedure controls for factors that can predetermine the weight of a baby, independent of an adverse fetal environment.
However, maternal factors can be difficult to access for midlife studies. In Aberdeen a database maintained since 1950 has given the opportunity to test the "fetal origins hypothesis" while controlling for these maternal factors. The aim of this study was to investigate whether there is a relationship between birth weight and midlife adult lung function and current wheeze, after controlling for maternal factors that influence birth weight. The analysis also took account of adult factors that affect current lung function such as smoking history, sex, age, height, and weight.

\section{METHODS}

\section{Study population}

In 1964 a random community survey of one in five children $(\mathrm{n}=2511)$ who attended school in Aberdeen reported that 288 children had wheeze, clinically defined as either asthma or wheezy bronchitis, and 2223 had no respiratory symptoms. ${ }^{910}$ In 1989 and 1994 follow up studies of the cohort were carried out to assess respiratory symptoms and lung function at various stages in adulthood. ${ }^{11}{ }^{12}$ These studies included a postal survey of all traceable subjects from the original 2511 children and interviews with 605 of them that included all traceable subjects who had wheeze as a child, together with a random sample of non-wheezy children.

In 2001 we followed up the 605 subjects who had been interviewed in 1989 and 1994. Of these, 78 had been diagnosed with childhood asthma, 111 with childhood wheezy bronchitis, 100 with adult onset wheeze, and 316 were controls who had had no respiratory symptoms as children. The addresses of these subjects were initially checked by Data Discoveries Ltd (Edinburgh) who confirmed the addresses and supplied possible new ones. The remainder were checked on the Patient Administration System (PAS) at Aberdeen Royal Infirmary for a current address. Finally, 
subjects for whom no current address could be found by either method were traced via the Community Health Index at Grampian Health Board.

A total of $592(98 \%)$ were traced by these methods, 381 (64\%) of whom agreed to participate and were tested for lung function. Factors that related to subjects agreeing to participate were level of affluence and smoking status at the time of the previous studies in 1989 and 1994. Affluence was measured by postcodes using the Carstairs deprivation index ${ }^{13} 14$ as classified into categories by McLoone et al. ${ }^{15} 16$ This index has been calculated on each postcode sector in Scotland from census data and combines information on household overcrowding, car ownership, male unemployment, and percentage of households where the head is in a semi-skilled or manual occupation. These values were then classified into seven categories where Depcat 1 represents the very affluent and Depcat 7 the severely deprived. Subjects from affluent areas (Depcat 1-3) were more likely to participate than subjects from less affluent areas (Depcat 47) $(71 \% \vee 56 \%, p<0.01)$. Subjects who either had never smoked or were ex-smokers at the time of the previous studies in 1989 or 1994 were more likely to participate than those who were current smokers in 1989 or $1994(p=0.01)$

In addition, the database at Aberdeen Maternity Hospital, Aberdeen Maternity and Neonatal Databank (AMND) was accessed. Since 1950, detailed information from obstetric and neonatal case records has been collected by specially trained staff with the objective of providing high quality research data. Records of all births from Aberdeen Maternity Hospital, Rubislaw Nursing Home, and home deliveries were collected. AMND is now fully computerised and birth data for 533 subjects born in Aberdeen ( $88 \%$ of original cohort) were extracted and matched by birth date, surname, mother's maiden name, and sex. ${ }^{17}$ Birth data extracted included gestation, birth weight, parity, mother's height and weight, and birth weight corrected for parity, gestation, sex, and mother's height and weight. Corrected birth weight scores were adjusted for weight of mother at booking of pregnancy. The maternal weight used was the first one recorded at a known gestation. This weight was then adjusted for gestation at booking. Multiple births were not included in the analysis for this study because the intrauterine environment of multiple pregnancies is different from singletons and the birth weight of twins is lower. ${ }^{8}$ Maternal smoking was not recorded in the databank at that time. However, maternal smoking data were extracted from the 1989 and 1994 questionnaires and classified by response to the question: "Did your mother smoke when you were a child?"

\section{Study protocol}

One researcher (CE) interviewed all subjects who agreed to participate between August 2000 and July 2001, either at the Chest Clinic in Aberdeen Royal Infirmary or in their own home. The interview included a modified version of the Medical Research Council's 1986 Respiratory Symptoms Questionnaire $^{18}$ and questions on current wheeze (past 12 months) and smoking. At the time of the interview $\mathrm{FEV}_{1}$ and FVC were measured using a portable spirometer (Vitalograph Compact II, Vitalograph, Buckingham, UK) which was calibrated daily. The spirometric measurements were performed with subjects in a sitting position without the use of nose clips. Three values were obtained and the highest $\mathrm{FEV}_{1}$ and FVC were used. Subjects prescribed a bronchodilator were requested not to use it for 6 hours before the tests were performed. Fifty one subjects had been prescribed bronchodilators, of whom five had used the bronchodilator within 6 hours of the tests being performed.

The study was approved by the Grampian Research Ethics Committee.

\section{Data analysis}

Statistical analyses were performed using SPSS 10.0 for Windows. FEV F $_{1}$ and FVC were expressed as litres. Linear regression was used to adjust adult lung function measurements for sex, height, weight, age, original childhood group, Depcat, current smoking status, and mother's smoking status. Corrected birth weight scores were calculated using standards published by Campbell et al and adjusted for maternal height and weight. The standardised birth weight was calculated according to the formula: birth weight mean birth weight (dependent on sex, parity and gestational age of baby)/standard deviation of birth weight (dependent on sex, parity and gestational age of baby). ${ }^{8}$ As described earlier, twins and triplets were excluded from the analysis.

\section{RESULTS}

Of the 372 participants who underwent lung function tests and who were not twins or triplets, birth details were available for $323(87 \%)$. Table 1 shows the characteristics of the 323 subjects in the present study. Smoking status did not differ greatly between men and women, nearly half the study population had never smoked and one quarter were current smokers. Just under one third of the population had current wheeze (last 12 months). Sex distribution and current smoking status of those who had maternal data did not differ from those who did not. Two hundred subjects (62\%) reported in 1989 or 1994 that their mother smoked during their childhood. Table 2 shows the characteristics of the mothers of these subjects at the time of birth.

In a one way analysis of variance a statistically significant positive linear trend in mean $\mathrm{FEV}_{1}$ and FVC (adjusted for adult age, height, weight, Depcat, childhood group, and subjects' smoking status) was observed between the unadjusted birth weight quintiles of both men and women (table 3). Using corrected birth weight scores, the statistically significant trend continued to be observed for men and women after adjusting for adult and maternal factors (table 4). After adjusting for maternal factors, the result for women appears to be explained mainly by an effect of the lowest quintile versus the other quintiles, in contrast to a clearer trend in men. No association was found between birth weight and $\mathrm{FEV}_{1} / \mathrm{FVC}$ ratio.

Using retrospective data on maternal smoking, a one way analysis of variance showed that birth weight, adjusted for maternal factors, was significantly lower in female babies born to mothers who smoked (mean (SD) corrected birth weight score $-0.412(0.92))$ than in babies born to mothers who did not smoke (mean (SD) corrected birth weight score

\begin{tabular}{lll}
\multicolumn{3}{c}{ Table 1 Characteristics of study population } \\
\hline & Men (n= 163) & Women $(\mathbf{n}=160)$ \\
\hline Age (years) & $47.7(1.5)$ & $47.7(1.5)$ \\
Height (cm) & $174.5(6.9)$ & $161.48(6.9)$ \\
Birth weight (g) & $3382(499)$ & $3222(498)$ \\
Corrected birth weight score & $-0.113(1.02)$ & $-0.215(1.10)$ \\
Smoking status & & \\
Never & $76(47 \%)$ & $78(49 \%)$ \\
Ex-smoker & $46(28 \%)$ & $38(24 \%)$ \\
Current smoker & $41(25 \%)$ & $44(27 \%)$ \\
Current wheeze & & \\
Yes & $51(31 \%)$ & $49(31 \%)$ \\
No & $112(69 \%)$ & $111(69 \%)$ \\
Depcat score & $101(62 \%)$ & $97(61 \%)$ \\
$1-3$ & $62(38 \%)$ & $63(39 \%)$ \\
$4-7$ &
\end{tabular}

Age, height, birth weight, and corrected birth weight score are shown as mean (SD).

Depcat score indicates deprivation category where $1=$ very affluent and $7=$ severely deprived. 
Table 2 Characteristics of subjects' mothers at time of birth $(n=323)$

\begin{tabular}{ll}
\hline Age (years)* & $27.2(5.5)$ \\
Height (cm)* & $158.2(5.5)$ \\
Gestation (weeks)* & $40.3(1.7)$ \\
Place of subjects' birth & \\
Aberdeen Maternity Hospital & $286(89 \%)$ \\
Home birth & $37(11 \%)$ \\
Parity & $124(38 \%)$ \\
0 & $99(31 \%)$ \\
1 & $65(20 \%)$ \\
2 & $21(7 \%)$ \\
3 & $10(3 \%)$ \\
4 & $4(1 \%)$ \\
5 or more & $200(62 \%)$ \\
Smoked during subjects' childhood & \\
\hline \multirow{2}{*}{ *Values shown as mean (SD). }
\end{tabular}

$0.072(1.28), p=0.01)$. There was no difference in adjusted birth weight of male babies whose mothers smoked. Adult lung function in males was not affected by controlling for maternal smoking. However, the $p$ value and $\beta$ coefficient in $\mathrm{FEV}_{1}$ in females was greater after controlling for maternal smoking (table 4).

A logistic regression analysis was carried out for wheeze in the past year in relation to birth weight score quintiles. Table 5 shows that the risk of wheeze, adjusted for current smoking status, did not alter as birth weight increased in either men $(p=0.72)$ or women $(p=0.75)$.

\section{DISCUSSION}

Barker et al hypothesised that an adverse environment in utero may affect fetal growth and have lasting effects on lung function in adulthood and old age. ${ }^{2}$ Our study found that low birth weight predicts lower lung function at mean age 47 years, controlling for maternal and adult factors, but did not find a relationship between birth weight and current wheeze in middle age. The relationship between lung function and birth weight in middle age supports the fetal origins hypothesis, and contrasts with the lack of relationship between middle age lung function and birth weight reported by Shaheen $e t a l^{4}$ and Lopuhää et al. ${ }^{5}$ The failure of these two groups to detect a relationship may reflect lesser variability in the samples they studied. In particular, the sample studied by Lopuhää et al was made up of adults who had all been born after their mothers had experienced famine in pregnancy. The population in our study is likely to include a wider range of lung function, from adults who have wheezed since childhood to controls who had no symptoms as children or as adults. This spectrum is more likely to provide sensitivity to detect a relationship between lung function and birth weight. However, because of the sampling process used in this study, specific lung function results cannot be generalised to the general population.

This study controlled for the adult factors that affect current lung function: age, sex, and height; adult weight was also adjusted for. It is of interest that the adjustment for adult weight had little effect on the relationship between birth weight and adult lung function. This would suggest that, although babies who are classified as underweight after adjustment for maternal factors may "catch up" with their peers in later life, their experience of poor fetal growth continues to be reflected in lower adult lung function.

However, this study did not find a relationship between birth weight and adult wheeze. We do not believe that this was due to lack of validity of the wheeze assessment. Our wheeze measurement was of the form: "Have you had wheezing or whistling in your chest at any time during the past 12 months and have you at any time in the last 12 months been woken at night by an attack of shortness of breath?" Wheeze at any time over the previous 12 months is the standard used by other studies investigating the relationship between current wheeze and epidemiological factors.

Previous studies have shown an association between birth weight and early adulthood symptoms. Shaheen et al found that the prevalence of wheeze in adults aged 26 years fell with increasing birth weight. ${ }^{19}$ Svanes et al found that, in subjects aged 20-24 years, asthma symptoms were inversely associated with birth weight. ${ }^{20}$ The findings of these studies-that birth weight is negatively related to symptoms-are not supported by Barker et $a^{2}$ or by our study. This may be due to confounding by a cohort effect ${ }^{21}$; adults now aged 50-70 years are likely to have had different environmental influences as children than present day young adults. The conflicting results might also be due to different wheezing phenotypes at different ages or to a lack of power in our study and that of Barker et al compared with the British cohort study of Shaheen et al ${ }^{19}$ and the European Community Respiratory Health Survey reported by Svanes et $a^{20}$ who had much bigger samples to analyse binary outcomes.

Alternatively, the relationship between childhood wheezing symptoms and adult lung function may be complex and influenced by the nature of childhood wheeze. We have previously reported that, in this cohort, childhood asthma was associated with reduced lung function at age 35-40 years whereas the children with wheezy bronchitis achieved normal lung function at that age. ${ }^{11}$ Interestingly, the group with childhood wheezy bronchitis is now showing a more rapid rate of decline in lung function than the normal controls. ${ }^{22}$

Table $3 \mathrm{FEV}_{1}$ and FVC values adjusted for age, height, weight, current smoking status, deprivation category (Depcat), and childhood group according to quintiles of unadjusted birth weight

\begin{tabular}{|c|c|c|c|c|c|c|c|c|c|c|}
\hline & \multicolumn{5}{|c|}{$\operatorname{Men}(n=163)$} & \multicolumn{5}{|c|}{ Women $(n=160)$} \\
\hline & $\mathbf{n}$ & $\mathrm{FEV}_{1}$ & $\begin{array}{l}\text { Difference } \\
\text { (95\% CI) }\end{array}$ & FVC & $\begin{array}{l}\text { Difference } \\
(95 \% \mathrm{Cl})\end{array}$ & $\mathbf{n}$ & $\mathrm{FEV}_{1}$ & $\begin{array}{l}\text { Difference } \\
\text { (95\% CI) }\end{array}$ & FVC & $\begin{array}{l}\text { Difference } \\
\text { (95\% CI) }\end{array}$ \\
\hline \multicolumn{11}{|c|}{ Unadjusted birth weight score (quintiles) } \\
\hline Lowest $20 \%$ & 26 & 3.10 & & 4.28 & & 40 & 2.29 & & 3.07 & \\
\hline $21-40 \%$ & 31 & 3.31 & $0.21(0.03$ to 0.40$)$ & 4.54 & $0.26(0.03$ to 0.49$)$ & 35 & 2.43 & 0.14 (0.02 to 0.28$)$ & 3.25 & 0.18 (0.05 to 0.32$)$ \\
\hline $41-60 \%$ & 32 & 3.27 & $0.17(-0.01$ to 0.35$)$ & 4.58 & 0.30 (0.07 to 0.52$)$ & 34 & 2.40 & $0.12(-0.01$ to 0.25$)$ & 3.22 & $0.15(0.01$ to 0.29$)$ \\
\hline $61-80 \%$ & 47 & 3.30 & $0.20(0.03$ to 0.37$)$ & 4.59 & $0.31(0.10$ to 0.52$)$ & 36 & 2.40 & $0.11(-0.01$ to 0.24$)$ & 3.23 & $0.16(0.03$ to 0.30$)$ \\
\hline Highest $20 \%$ & 27 & 3.37 & $0.27(0.08$ to 0.46$)$ & 4.70 & $0.42(0.18$ to 0.65$)$ & 15 & 2.49 & $0.18(0.03$ to 0.37$)$ & 3.34 & $0.27(0.09$ to 0.45$)$ \\
\hline$\beta$ coefficient & & 0.18 & & 0.25 & & & 0.17 & & 0.23 & \\
\hline $\mathrm{p}$ for trend & & 0.02 & & $<0.01$ & & & 0.03 & & $<0.01$ & \\
\hline \multicolumn{11}{|c|}{ Adjusted for maternal smoking } \\
\hline$\beta$ coefficient & & 0.18 & & 0.25 & & & 0.26 & & 0.23 & \\
\hline $\mathrm{p}$ for trend & & 0.02 & & $<0.01$ & & & $<0.01$ & & $<0.01$ & \\
\hline
\end{tabular}

Forced expiratory volume in 1 second $\left(\mathrm{FEV}_{1}\right)$ and forced vital capacity $(\mathrm{FVC})$ values are shown as mean. 
Table 4 FEV $1, F V C$ values, adjusted for age, height, weight, current smoking status, Depcat, and childhood group according to quintiles of corrected birth weight score*

\begin{tabular}{|c|c|c|c|c|c|c|c|c|c|c|}
\hline & \multicolumn{5}{|c|}{ Men $(n=163)$} & \multicolumn{5}{|c|}{ Women $(n=160)$} \\
\hline & $\mathrm{N}$ & $\mathrm{FEV}_{1}$ & Difference $(95 \% \mathrm{Cl})$ & FVC & Difference $(95 \% \mathrm{Cl})$ & $\mathbf{n}$ & $\mathrm{FEV}_{1}$ & Difference $(95 \% \mathrm{Cl})$ & FVC & Difference $(95 \% \mathrm{Cl})$ \\
\hline \multicolumn{11}{|c|}{ Corrected birth weight score (quintiles) } \\
\hline Lowest $20 \%$ & 31 & 3.19 & & 4.39 & & & 33 & 2.25 & & 3.04 \\
\hline $21-40 \%$ & 35 & 3.25 & $0.06(-0.11$ to 0.23$)$ & 4.51 & $0.12(-0.10$ to 0.33$)$ & 30 & 2.46 & $0.19(0.07$ to 0.35$)$ & 3.27 & 0.23 (0.08 to 0.38$)$ \\
\hline $41-60 \%$ & 26 & 3.24 & $0.05(-0.13$ to 0.24$)$ & 4.53 & $0.14(-0.09$ to 0.37$)$ & 32 & 2.38 & $0.14(-0.01$ to 0.26$)$ & 3.19 & 0.15 (0.01 to 0.30$)$ \\
\hline $61-80 \%$ & 39 & 3.33 & $0.14(-0.03$ to 0.31$)$ & 4.63 & $0.24(0.03$ to 0.45$)$ & 33 & 2.45 & $0.19(0.06$ to 0.33$)$ & 3.27 & 0.23 (0.09 to 0.38$)$ \\
\hline Highest 20\% & 32 & 3.35 & $0.16(-0.01$ to 0.34$)$ & 4.65 & $0.26(0.04$ to 0.48$)$ & 32 & 2.41 & $0.16(0.02$ to 0.30$)$ & 3.24 & 0.20 (0.05 to 0.34$)$ \\
\hline$\beta$ coefficient & & 0.16 & & 0.20 & & & 0.16 & & 0.19 & \\
\hline $\mathrm{p}$ for trend & & 0.04 & & 0.01 & & & 0.04 & & 0.02 & \\
\hline \multicolumn{11}{|c|}{ Adjusted for maternal smoking } \\
\hline$\beta$ coefficient ${ }^{*}$ & & 0.16 & & 0.27 & & & 0.25 & & 0.20 & \\
\hline $\mathrm{p}$ for trend* & & 0.04 & & 0.01 & & & $<0.01$ & & $<0.01$ & \\
\hline
\end{tabular}

Barker et $a^{2}$ did not find an association between FVC and birth weight, in contrast to our findings and those of Stein et al. ${ }^{3}$ The significance of FVC in such studies is more difficult to interpret than $\mathrm{FEV}_{1}$. It is well recognised that FVC may be reduced in obstructive lung disease where it reflects early airway closure and gas trapping. Both subject technique and equipment used to measure FVC may influence the results obtained, and none of the studies reported to date can definitively address whether the FVC measures obtained reflect obstructive or restrictive aspects of function.

The birth data collected for our subjects in the 1950s by AMND were more limited than would now be available. In particular, the measurement of baby length, which allows calculation of ponderal index, was not done. Ponderal index is the ratio of birth weight to length and is an indicator of fatness or thinness of the neonate. However, the AMND did provide more maternal information than other studies of cohorts of similar age. The use of Campbell's birth weight standards ${ }^{8}$ removed any inherent factors that might affect birth weight independent of poor fetal growth. Controlling for the factors essentially had no effect on the association between birth weight and adult lung function. This lends strength to the argument that an adverse environment in utero has independent effects on midlife and elderly lung function.

However, this study contributes little to our knowledge of what may cause this adverse environment. Maternal smoking $^{23}{ }^{24}$ and diet $^{25}{ }^{26-28}$ have been cited as possible factors, but in the 1950s these were not recorded routinely. Our only indicator of maternal smoking is the report by subjects in the studies of 1989 and 1994 (aged between 30 and 40 years at this time) of whether their mother smoked during their early childhood. This study found a relationship between reported maternal smoking and birth weight among female subjects but not for males, and no relationship between reported

Table 5 Association between current wheeze (past 12 months) and corrected birth weight score

\begin{tabular}{llll}
\hline $\begin{array}{l}\text { Corrected birth } \\
\text { weight score } \\
\text { (quintiles) }\end{array}$ & Men & & Women \\
\cline { 2 - 2 } & *OR $(95 \% \mathrm{Cl})$ & & *OR $(95 \% \mathrm{Cl})$ \\
\hline Lowest $20 \%$ & 1 & 1 \\
$21-40 \%$ & $0.87(0.30$ to 2.50$)$ & & $0.63(0.21$ to 1.93$)$ \\
$41-60 \%$ & $0.85(0.27$ to 2.65$)$ & & $1.18(0.42$ to 3.27$)$ \\
$61-80 \%$ & $0.80(0.28$ to 2.26$)$ & & $1.04(0.37$ to 2.91$)$ \\
Highest $20 \%$ & $0.45(0.14$ to 1.43$)$ & & $0.68(0.23$ to 2.00$)$ \\
& $p=0.72$ & $p=0.75$ \\
\hline
\end{tabular}

*Odds ratios (OR) derived from logistic regression analyses are for upper tertiles compared with lower tertile including adjustment for smoking status. maternal smoking and midlife lung function. However, these results can only be exploratory in nature because of the imprecise data used. In essence, all that we are controlling for is whether the mother had "ever smoked" in the subject's childhood; we cannot be sure that they smoked at the time of pregnancy.

The results of this study support the "fetal origins hypothesis" that an adverse environment in utero can affect fetal growth and influence lung function in mid adult life, and that birth weight is a marker for adult lung function. By controlling for maternal and adult factors, the case has been strengthened. However, birth weight was not a marker for wheeze in middle age.

\section{ACKNOWLEDGEMENTS}

The authors thank Joyce Leys for her technical support, Mary Bruce for scanning the questionnaires, Jean Wood for her assistance with invitation letters at Grampian Health Board, and Frances Findlay for her help in extracting data from the original maternal records.

\section{Authors' affiliations}

C A Edwards, L M Osman, J G Douglas, Respiratory Unit, Aberdeen Royal Infirmary, Aberdeen AB25 2ZN, UK

D J Godden, Highland \& Islands Health Research Institute, Inverness IV2 3ED, UK

D M Campbell, Department of Obstetrics \& Gynaecology, University of Aberdeen, Aberdeen Maternity Hospital, Aberdeen AB25 2ZD, UK

The study was funded by Chest, Heart and Stroke, Scotland.

\section{REFERENCES}

1 Stick S. Pediatric origins of adult lung disease. 1. The contribution of airway development to paediatric and adult lung disease. Thorax 2000;55:587-94.

2 Barker DJ, Godfrey KM, Fall C, et al. Relation of birth weight and childhood respiratory infection to adult lung function and death from chronic obstructive airways disease. BMJ 1991;303:671-5.

3 Stein CE, Kumaran K, Fall CH, et al. Relation of fetal growth to adult lung function in south India. Thorax 1997:52:895-9.

4 Shaheen SO, Sterne JA, Tucker JS, et al. Birth weight, childhood lower respiratory tract infection, and adult lung function. Thorax 1998;53:549-53.

5 Lopuhaa CE, Roseboom TJ, Osmond C, et al. Atopy, lung function, and obstructive airways disease after prenatal exposure to famine. Thorax 2000:55:555-61

6 Scott A, Moar V, Ounsted M. The relative contribution of different maternal factors in large-for-gestational-age pregnancies. Eur J Obstet Gynecol Reprod Biol 1982;13:269-77.

7 Gardosi J, Mongelli M, Wilcox $M$, et al. An adjustable fetal weight standard. Ultrasound Obstet Gynecol 1995:6:168-74.

8 Campbell D, Hall M, Lemon J, et al. Clinical birthweight standards for a total population in the 1980s. Br J Obstet Gynaecol 1993; 100:436-45.

9 Illsley R, Wilson F. The Aberdeen child development survey. In: Mednick SA ed. Prospective longitudinal research: an empirical basis for the primary prevention of psychological disorders. Oxford: Oxford Medical Publications, 1981:66-8.

10 Dawson B, Illsley R, Horobin G, et al. A survey of childhood asthma in Aberdeen. Lancet 1969;1:827-30. 
11 Godden DJ, Ross S, Abdalla M et al Outcome of wheeze in childhood. Symptoms and pulmonary function 25 years later. Am J Respir Crit Care Med 1994; 149:106-12.

12 Bodner C, Ross S, Douglas G, et al. The prevalence of adult onset wheeze: longitudinal study. BMJ 1997;314:792-3.

13 Carstairs V. Deprivation indices: their interpretation and use in relation to health. J Epidemiol Community Health 1995;49(Suppl 2):S3-S8.

14 Morris R, Carstairs V. Which deprivation? A comparison of selected deprivation indexes. J Public Health Med 1991;13:318-26.

15 McLoone P, Boddy FA. Deprivation and mortality in Scotland, 1981 and 1991. BMJ 1994;309: 1465-70.

16 Mcloone P. Targeting deprived areas within small areas in Scotland: population study. BMJ 2001;323:374-5.

17 Samphier M. Thompson B. The Aberdeen maternity and neonatal databank. In: Mednick SA, Baert AE, eds. Prospective longitudinal research. London: Oxford University Press, 1982.

18 National Occupational Health \& Safety Commission, Australia. Questionnaire on respiratory symptoms. 2001. Available at http:// www.nohsc.gov.au/OHSInformation/NOHSCPublications.

19 Shaheen SO, Sterne JA, Montgomery SM, et al. Birth weight, body mass index and asthma in young adults. Thorax 1999;54:396-402.
20 Svanes C, Omenaas E, Heuch JM, et al. Birth characteristics and asthma symptoms in young adults: results from a population-based cohort study in Norway. Eur Respir J 1998;12:1366-70.

21 Susser M. Commentary: the longitudinal perspective and cohort analysis. Int J Epidemiol 2001:30:684-7.

22 Edwards CA, Osman LM, Godden DJ, et al. Wheezy bronchitis in childhood: a distinct clinical entity with lifelong significance? Chest 2003;124:18-24.

23 Matsubara F, Kida M, Tamakoshi A, et al. Maternal active and passive smoking and fetal growth: a prospective study in Nagoya, Japan. J Epidemiol 2000; 10:335-43.

24 Wang X, Zuckerman B, Pearson C, et al. Maternal cigarette smoking, metabolic gene polymorphism, and infant birth weight. JAMA 2002;287:195-202.

25 Godfrey K, Robinson S, Barker DJ, et al. Maternal nutrition in early and late pregnancy in relation to placental and fetal growth. BMJ 1996:312:410-4.

26 Mathews F, Yudkin P, Neil A. Influence of maternal nutrition on outcome of pregnancy: prospective cohort study. BMJ 1999;319:339-43.

27 Campbell DM, Hall MH, Barker DJ, et al. Diet in pregnancy and the offspring's blood pressure 40 years later: 3. Br J Obstet Gynaecol 1996:103:273-80.

28 Shiell AW, Campbell DM, Hall MH, et al. Diet in late pregnancy and glucoseinsulin metabolism of the offspring 40 years later: 1. Br J Obstet Gynaecol 2000;107:890-5.

\section{Scadding-Morriston Davies Joint Fellowship in Respiratory Medicine 2004}

This fellowship is available to support visits to medical centres in the UK or abroad for the purpose of undertaking studies related to respiratory medicine. Applications are invited from medical graduates practising in the UK, including consultants and irrespective of the number of years in that grade. There is no application form but a curriculum vitae should be submitted together with a detailed account of the duration and nature of the work and the centres to be visited, confirming that these have agreed to provide the facilities required. Please state the sum of money needed for travel and subsistence. A sum of up to $£ 20000$ can be awarded to the successful candidate, or the sum may be divided to support two or more applications. Applications should be sent to Dr I A Campbell, Secretary to the ScaddingMorriston Davies Fellowship, Llandough Hospital, Penarth, Vale of Glamorgan CF64 2XX, UK by 31 January 2004 